\title{
AS CONTRIBUIÇÕES SOBRE A HISTÓRIA DA EDUCAÇÃO INFANTIL NO BRASIL ENTRE 1875 - 1983
}

MONARCHA, Carlos (org.). Educação da infância brasileira 1875 - 1983. Campinas, SP: Autores Associados, 2001. 270 p.

Resenhada por:

Edaniele Cristine Batista Machado ${ }^{1}$

Carlos Herold Junior ${ }^{2}$

A leitura de "Educação da infância brasileira 1875-1983" ocorreu por conta de nosso interesse pelo estudo sobre a história da educação infantil no Paraná e na cidade de Guarapuava. A inexistência de estudos históricos que focalizem o recorte especial reduzido ao contexto guarapuavano, tem nos levado a um caminho de pesquisa duplo: a) a busca de fontes que nos permitam focalizar a educação das crianças, tanto nas instituições educacionais, quanto nos âmbitos extra-escolares; 2) $\mathrm{O}$ aparelhamento teórico por meio de estudos que analisam a educação infantil na história educacional brasileira e mundial. Essa ampliação do conhecimento da literatura existente sobre a história dessa faceta educacional, tem sido feita para que ela nos possibilite a condição analítica privilegiada para estudo das fontes que temos encontrado. Por isso, a leitura da coletânea organizada por Carlos Monarcha foi um dos momentos mais ricos desse processo de pesquisa.

Carlos Monarcha é professor adjunto na Faculdade de Filosofia e Ciências (FFC) da UNESP. É autor de várias obras de grande relevância sobre a história da educação brasileira: A reinvenção da cidade e da multidão: dimensões da modernidade brasileira a Escola Nova (Cortez/ Autores Associados); Escola Normal da Praça: o lado noturno das luzes (Ed. da UNICAMP); e co-autor de Por Lourenço Filho: uma bibliografia (INEP). Da produção mais recente do pesquisador, Brasil arcaico, escola nova, com o qual Monarcha foi indicado ao Prêmio Jabuti, amplia o conjunto de toda uma produção que tem oferecido contribuições de grande valor para compreendermos os desdobramentos históricos da educação brasileira.

Em Educação da infância brasileira (1875-1983) Monarcha reúne pesquisas sobre a instituição das escolas infantis e a difusão da escola elementar pública no mundo ocidental do século XIX. O livro está organizado em oito capítulos. Neles, além de termos textos de pesquisadores já amplamente conhecidos sobre a história da infância e de sua educação, há também autores que divulgam pesquisas efetivadas em suas teses de doutorado ou dissertação de mestrado. Esse rico conjunto formado por pesquisadores "seniores" e "juniores", permite a obra apresentar um rico panorama sobre nossa história educacional.

No primeiro capítulo, Moysés Kuhlmann Jr., discute o "O Jardim-de-Infância e a Educação das Crianças Pobres". Focalizando o final do século XIX e início do século XX, o autor traz a história das primeiras instituições de educação infantil no continente Europeu, suas intenções pedagógicas e sua propagação internacional. Primeiramente Kuhlmann Jr. destaca que a interpretação sobre a história da educação infantil, acompanhada das instituições para as crianças pobres, das creches e salas de asilo, tiveram uma identidade distinta do jardim de infância, distante das preocupações educacionais. Porém, o autor, baseado em fontes européias, descreve o desenvolvimento dessas instituições e afirma que havia uma proposta pedagógica, mesmo sendo ela uma pedagogia com o objetivo de disciplinar e apaziguar relações sociais. Quanto à propagação 
internacional do jardim de infância, o autor coloca que no final do século XIX a crescente expansão das relações internacionais, levou as instituições de educação infantil a vários países prevendo regular a vida social envolvida na crescente industrialização e urbanização. Para finalizar, Kuhlmann Jr. ressalta que as evidencias históricas mostram a estreita relação entre o assistencialismo e a educação, mas que essas evidências são deixadas de lado pelos estudos que atribuem aos jardins de infância uma dimensão educacional e não assistencial. Segundo o autor, no final do século XIX a assistência foi privilegiada nas políticas de atendimento à infância em instituições educacionais, como nas que ocorriam nos jardins-da-infância, creches e escolas maternais.

O segundo capítulo, escrito por Maria Helena Camara Bastos, traz o título "Jardim de Crianças e o Pioneirismo do Dr. Menezes Vieira (1875 - 1887)". Nele a autora estuda os principais aspectos que caracterizavam a versão médica do projeto de ordem social para regenerar e modernizar o País em meados do século XIX. A autora privilegia o pioneirismo do Dr. Menezes Vieira na criação dos jardins-de-infância no Brasil. Camara Bastos, analisa a organização do Jardim das crianças instituído pelo médico, desde o método Froebeliano por ele utilizado, passando pela direção da Sra. Carlota de Menezes Vieira, a formação das professoras, chegando até obra produzida pelo Dr. Menezes Vieira sobre o tema jardim-de-infância. É destacada a importância da educação moral e da higiene das crianças. Outro ponto importante colocado pela autora é a participação do médico na Exposição Pedagógica de 1883 em defesa da criação dos jardins-de-infância por todo o país, sendo essas alvos de muitas discordâncias por se tratarem de uma instituição privada longe das responsabilidades do Estado para com esse nível de ensino. Nas conclusões ao capítulo, Camara Bastos observa que os jardins-de-infância foram restritos a uma pequena parcela da sociedade. Afinal, somente no final do século XX o Estado assegurou o direito à educação para todas as crianças de 0 a 7 anos.

Carlos Monarcha é o responsável pelo terceiro capítulo, com o título "Revista do Jardim da Infância - uma publicação exemplar". O autor traz o processo de criação do Jardim-da-Infância anexo à Escola Normal de São Paulo, assim como, os documentos e artigos publicados na Revista do Jardim da Infância. Monarcha descreve pontualmente a organização das duas publicações, respectivamente de 1896 e 1897, com grande quantidade de ilustrações e de artigos sobre concepções e práticas sobre o chamado "ensino infantil". O objetivo era fundamentar, institucional e didaticamente, o Jardim-daInfância segundo os princípios de Froebel. A publicação das revistas, afirma Monarcha, foi alvo de reações contraditórias e tensas. Todavia elas se consolidaram como um reconhecido manual pedagógico dos processos Froebelianos, adotados no Jardim-daInfância anexo à Escola Normal da São Paulo. Por isso, Monarcha considera que, mesmo tendo somente duas publicações, a Revista desempenhou um papel exemplar no cenário cultural e educacional do final do século XIX e início do século XX, inaugurando uma reflexão original sobre a educação da infância brasileira.

"Crianças como Agentes do Processo de Alfabetização no Final do Século XIX e Início do XX”, é o título do quarto capítulo escrito por Zeila de Brito Fabri Demartini. Nele a autora discute algumas questões da história da leitura e da história da infância na passagem do século XIX para o século XX em São Paulo. A partir da análise de relatos orais de pessoas que viveram suas infâncias neste período, a pesquisadora afirma que há uma correspondência entre o que está nas memórias e os temas atuais de estudos sobre a infância. Com isso, é observado que não se pode falar de uma infância "genérica", pois, como constata, as infâncias nas primeiras décadas da República foram muitas, advindas de diversas origens e experiências, tanto sociais como culturais, ou seja, as crianças passaram por diferentes histórias, especialmente no que diz respeito à educação. No decorrer de sua 
pesquisa a autora mostra que neste período o processo de leitura e escrita iniciava-se antes da entrada na escola primária. Embora o acesso à escola ainda fosse restrito a um número pequeno de entrevistados, demonstra-se que a aprendizagem não foi uma experiência vivenciada apenas entre as crianças da elite paulista, mas também pelos excluídos socialmente, mesmo sendo providenciado pelas próprias crianças. Sobre o processo de alfabetização das crianças negras, Demartini aponta que estas foram marginalizadas e excluídas do sistema educacional, acabando por se organizarem entre si para aprenderem a ler e a escrever umas com as outras, tornando-se preocupação do Estado somente sobre a problemática do "menor", sendo inseridas em um projeto de encaminhamento para o trabalho e bons costumes. E, sobre a alfabetização das crianças das populações rurais, o processo não foi diferente, pois eram praticamente excluídas das políticas públicas voltadas para a educação escolar entre o final do século XIX e inicio do século XX, e que também se alfabetizavam umas com as outras.

O quinto capítulo é escrito por Alessandra F. Martinez de Schueler, e traz o título “A Associação Protetora da Infância Desvalida e as Escolas de São Sebastião e São José Educação e Instrução no Rio de Janeiro do século XIX". Nele a autora analisa a história do nascimento das primeiras escolas públicas destinadas ao ensino primário no Rio de Janeiro, das participações políticas, comerciais e religiosas e, da criação em 1871, da Associação Municipal Protetora da Infância Desvalida. Schueler aponta que a finalidade da Associação era garantir a presença das crianças desvalidas e pobres nas escolas criadas pela Câmara Municipal. A instrução primária era encarada como um instrumento político de controle sobre as camadas pobres da sociedade. Por isso a escola municipal deveria representar não só um espaço para a aquisição dos conhecimentos elementares, mas também ser um espaço de educação moral e religiosa. Esse direcionamento visava à formação de um cidadão útil, moralizado e integrado aos sentimentos de amor a Deus, ao trabalho e à Pátria. Como coloca a autora, um projeto de construção de uma nação, guiado pelos padrões de civilização e progresso dos países considerados mais adiantados.

Leila de Andrade Oliveira é responsável pelo sexto capítulo, intitulado "A Experiência Educacional de Ulisses Pernambucano". A autora investiga o pioneirismo de Ulisses Pernambucano no âmbito educacional. Médico, psiquiatra, psicólogo e educador, Ulisses Pernambucano de Mello Sobrinho (1892-1943) nascido em Recife e formado no Rio de Janeiro, passou pelas transformações ocorridas no Brasil nos finais do século XIX, como a Proclamação da República e a Abolição da Escravidão. Oliveira constata o interesse do médico em relação ao campo psicopedagógico e social. Esse interesse o levou a desenvolver seu trabalho sobre a psiquiatria social e a criança excepcional, lançando-se sobre o ensino público com a intenção de higienizar a escola por meio de um redirecionamento dos métodos de ensino, bem como propondo uma organização escolar que contemplasse também os atrasados. Sobre isso a autora salienta que, através da atuação como diretor de escolas e institutos, Ulisses Pernambucano deixou transparecer seu pragmatismo, sua capacidade renovadora e a coerência entre seus ideais e métodos utilizados para alcançar seus objetivos, visando sempre à coletividade. O pioneirismo de Ulisses Pernambucano quanto à criação de Institutos voltados à educação das crianças excepcionais fez com que o problema da educação especial fosse levantado por todo o país, deixando de ser oculto, abandonado ou, mesmo, de se buscar soluções.

O sétimo capítulo, "A Emoção e a Regra na Construção de uma Pedagogia da Infầncia", escrito por Suely Amaral Mello, trata de uma experiência positiva sobre a educação das crianças menores de 6 anos no Brasil dos anos 1990, especificamente no município de Piracicaba/SP. Neste estudo, a autora relata que a diretriz norteadora do programa era desenvolver nas crianças da educação infantil e das séries iniciais do ensino 
fundamental o máximo das possibilidades humanas - formar cada ser humano para ser um dirigente, dentro da perspectiva gramsciana. Mello chama atenção, também, ao processo de formação dos educadores que atuaram no Programa. Sendo essa formação continuada, com palestras, reuniões, cursos, troca de experiências entre os educadores, discussões políticas, participação em congressos e simpósios, tais atividades objetivavam a educação política e a apropriação de instrumentos para a autonomia intelectual. Pois estes seriam os transformadores daquela sociedade. A autora conclui que, embora naquele momento estivessem mais preparados para pensar o político do que o educacional propriamente, o projeto pedagógico para as crianças nos primeiros anos de vida, foi muito bem estruturado, garantindo a muitas crianças o direito à infância e obedecendo cada fase do seu desenvolvimento.

Anamaria Santana da Silva e Meriete Félix Rosa finalizam a obra com o oitavo capítulo, "Recordando e Colando - As origens da Educação Infantil nas Escolas Públicas de Mato Grosso do Sul". As autoras apresentam os resultados da pesquisa a respeito das origens da educação infantil em Mato Grosso do Sul durante os anos 1970, quando foi implantado pela secretaria Estadual o projeto Casa-Escola Infantil do Bom Senso. É descrito o trabalho pedagógico realizado com as crianças, a concepção de criança e de infância presente no projeto, o espaço físico da casa-escola, os cursos e a formação das professoras, o trabalho da equipe de coordenação, a participação dos pais, a clientela atendida, enfim, as formas de desenvolvimento do projeto. As pesquisadoras ponderam que a implantação do projeto Casa-Escola Infantil do Bom Senso como proposta de educação das crianças pequenas, significou um marco para a educação infantil pública no estado de Mato Grosso do Sul.

Uma característica positiva da obra é a unidade dos capítulos, trazendo pesquisas baseadas em um amplo escopo de fontes como relatórios, revistas, fotografias, observações e relatos orais. Outro ponto que poderíamos apontar como traço que sublinha a importância da coletânea, é a ampla cobertura temporal dada pelo conjunto dos textos, fazendo com que muitos pesquisadores possam encontrar subsídios e sinalizações importantes para suas pesquisas. Mesmo que a maioria dos textos focalize o final do século XIX, algumas reflexões chegam ao final do século XX. Com as escolhas referentes aos recortes temporais utilizados no texto, o livro, ao mesmo tempo, sinaliza um caminho já amplamente percorrido pelos estudiosos da história da educação infantil, ao mesmo tempo em que estimula a realização de estudos sobre os desdobramentos históricos das últimas décadas no que concerne à educação infantil.

Tanto pelas escolhas já consagradas, quanto por indicar possibilidades de avanços em outras direções analíticas, recomendamos a leitura de "Educação da infância brasileira (1875-1983)" a todos aqueles que se interessam pela infância e por sua educação na história.

Notas

\footnotetext{
${ }^{1}$ Acadêmica do curso de Pedagogia - Docência e Gestão Educacional da UNICENTRO - Universidade Estadual do Centro-Oeste - Guarapuava/PR.

${ }^{2}$ Professor Adjunto do Departamento de Pedagogia da UNICENTRO - Universidade Estadual do CentroOeste - Guarapuava/PR.
} 